\title{
Paradigma, ética y gestión (a propósito de la responsabilidad social)
}

\author{
BALTAZAR CARAVEDO*
}

\begin{abstract}
SUMARIO: INTRODUCCIÓN.- I. DESARROLLO SOSTENIBLE Y ÉTICA.II. NUEVO PARADIGMA.- III. NUEVA ÉTICA.- IV. NUEVA GERENCIA.- V. EL PROCESO DE LA RESPONSABILIDAD SOCIAL EN EL PERÚ.-
\end{abstract}

\section{INTRODUCCIÓN}

Hace dieciocho años ${ }^{1}$, se iniciaron en el Perú los primeros esfuerzos por generar un acercamiento teórico a la perspectiva y a la práctica de la responsabilidad social en el sector empresarial. Hace once años ${ }^{2}$, se realizaron los primeros estudios sobre prácticas de responsabilidad social de empresas (RSE), investigación pionera no solo en nuestro país sino, también, en América Latina. El foco de atención inicial se ha expandido y hoy abarca a todo tipo de instituciones (empresas, organizaciones de la sociedad civil, instituciones públicas). La perspectiva se ha convertido en un discurso generalizado y en una necesidad vinculada a las nuevas exigencias de los consumidores y clientes, del mundo académico y, en general, de los ciudadanos.

En el actual contexto peruano, el proceso de la responsabilidad social debe contener un propósito múltiple.

- En primer lugar, debe crear las mejores condiciones para una adecuada gobernabilidad en nuestro país y generar una oportunidad para hacer una reflexión crítica que contribuya a mejorar las estrategias y las políticas de las instituciones.

- En segundo lugar, debe reposicionar el tema de la responsabilidad social como una práctica que no solo guíe el accionar de las empresas privadas sino, del diverso tipo de instituciones que existen en nuestra sociedad (privadas con fines de lucro, privadas sin fines de lucro, públicas y, en general, organizaciones de la sociedad civil).

* Es director de la Escuela de Liderazgo de la Universidad del Pacífico, presidente de SASE y coordinador del Proyecto Responsabilidad Social TODOS. Ha sido representante de la Fundación AVINA en el Perú y Ecuador hasta fines de 2006, director del Sistema de Apoyo Local de la Inter-American Foundation entre 1988 y 2000, y colaborador científico del Centro de Estudios y Documentación Latino Americano (CEDLA), en Ámsterdam, Holanda. Ha publicado veintiún libros, diez de los cuales están referidos a temas de responsabilidad social.

1 Una reflexión que sintetiza las ideas centrales de ese momento se puede encontrar en CARAVEDo, Baltazar. Empresa, liderazgo y sociedad. (Hacia una estrategia de responsabilidad social). Lima: Perú 2021 y SASE, 1996.

2 Véase CARAVEDO, Baltazar. Responsabilidad social de la empresa: un eje para cambiar el país. Lima: Perú 2021 y SASE, 1998; y del mismo autor Perú: empresas responsables. Lima: SASE y Perú 2021, 1998; así como Lo social y la empresa a fines de siglo. Lima: Universidad del Pacífico, Perú 2021 y SASE, 1999. 
- En tercer lugar, debe potenciar la competitividad del país al incorporar en las empresas y demás instituciones la responsabilidad social como estrategia de crecimiento económico y desarrollo sostenible en el marco de la globalización.

- En cuarto lugar, debe contribuir al proceso de integración, reconocimiento de la diversidad, reconocimiento del otro y diálogo que supone el ser parte de una sociedad cohesionada y, por ello, inclusiva, en la que se puedan reducir las tensiones sociales negativas y potenciar las positivas, con lo cual se minimicen las oportunidades de emergencia de confrontaciones y conflictos destructivos.

- En quinto lugar, debe ayudar al proceso de compromiso ético y de transformación de los distintos actores de la sociedad peruana.

Nuestra propuesta es que, si modificamos las prácticas en nuestras organizaciones, y si estas se sostienen en el tiempo, dado que conforman espacios educativos, finalmente lograremos construir nuevos hábitos, conductas, afectos, sentimientos y actitudes. La responsabilidad social vista como una nueva ética puede ser un eje transformador.

\section{DESARROLLO SOSTENIBLE Y ÉTICA}

La preocupación por el desarrollo ha tenido distintos elementos teóricos de base. Inicialmente, se formuló la idea de que el desarrollo era económico y de que se materializaba por etapas. Se admitía que una vez superadas los países llegarían a obtener un nivel de desarrollo similar. La gran cuestión era acelerar su llegada. Y para ello se requerían determinadas condiciones. Para algunos, la más importante era contar con un sector económico interno que produjese bienes de capital (maquinarias y equipos) para producir los bienes y los servicios que la población requería, no solo para subsistir, sino para educarse, entretenerse y llevar, en general, una vida saludable. Pero, para contar con un sector productor de bienes de capital se necesitaba una capacidad de generación de excedentes que, en los países menos desarrollados, no existía. La inversión extranjera era considerada necesaria.

También se pensó sobre cómo lograr el incentivo para el desarrollo. Y en este punto apareció la preocupación por la intervención del Estado y los mecanismos de la planificación y el mercado. En otras palabras, iquién debía impulsar el desarrollo y a través de qué mecanismos?: ¿el Estado, vía políticas de planificación obligatoria?, io el mercado, orientado con incentivos tributarios, arancelarios, de tipo de cambio, de crédito, etcétera?

Posteriormente, apareció la preocupación por asociar desarrollo económico y naturaleza de gobierno. ¿Daba lo mismo si el desarrollo económico era impulsado por una dictadura o por una democracia? iEl desarrollo económico es independiente del carácter democrático o no de 
los gobiernos y de sus respectivas sociedades? ¿Desarrollo económico solamente? ¿Desarrollo económico y democracia? Estas preguntas redefinían la naturaleza exclusivamente económica del desarrollo. En el marco de este cuestionamiento, también se hablaba de desarrollo, a secas, que involucraba aspectos distintos de un mismo proceso.

Más tarde apareció la noción de desarrollo humano. Con este criterio, se quiso destacar que las personas y sus sociedades no solo eran agentes económicos sino sujetos históricos que necesitaban de otros elementos, además de los ingresos económicos, para vivir armónicamente. Es posible que las preocupaciones por las identidades colectivas de naturaleza étnica, lingüística o cultural surgieran a partir de una visión crítica de la noción economicista. La concepción de desarrollo humano ponía el énfasis en condiciones de salud, educación, identidad cultural, entre otras.

La visión de desarrollo sostenible surgió con la preocupación ambiental, pero no se limitó a esta. Con su introducción no solo se ampliaba el espectro de elementos a considerar para hablar de desarrollo. En este caso, se incluía el medio ambiente. Pero, además, se preguntaba por la posibilidad de la continuidad del desarrollo en las generaciones futuras, al menos, en las mismas condiciones que en las generaciones presentes. Buscó la equidad intergeneracional.

En el marco de esta perspectiva es que surgió la definición de sostenibilidad como la articulación de procesos en la dimensión ambiental, económica y social. Hoy los gobiernos, las empresas y, en general, las instituciones que actúan con una perspectiva de desarrollo sostenible emplean como referente lo que llaman «la triple línea de base» (económica, ambiental y social). Los reportes de sostenibilidad incluyen estos tres aspectos para dar cuenta de la manera en que operan las instituciones. El desarrollo sostenible se ha constituido en una ética.

\section{NUEVO PARADIGMA}

Un paradigma es una estructura de pensamiento y afecto con la que interpretamos los mundos por los que nos desplegamos. Por ejemplo, el paradigma con el que solemos percibir las empresas es el de instituciones voraces, deseosas de obtener más y más utilidades, despreocupadas de lo que les ocurre a sus trabajadores o del daño medio ambiental que generan. El paradigma con el que interpretamos a los políticos es el de personas interesadas en la acumulación de poder individual, proclives a la corrupción, alejados de un deseo genuino de representación de quienes votaron por ellos.

Basándome en estos paradigmas juzgo el quehacer de las empresas o de los políticos. Si una empresa desarrolla un programa de inversiones ambientales y sociales para paliar los efectos de la contaminación de su proceso productivo, juzgaré que lo hace para producir más ganancias y no para cuidar el bienestar de la población que se encuentra en su área

PARADIGMA,

ÉTICA Y GESTIÓN (A PROPÓSITO DE LA RESPONSABILIDAD SOCIAL) 
de influencia. Si el representante de una fuerza política en el Congreso de la República presenta un proyecto de ley para proteger a los minusválidos, analizaré su propuesta desde la perspectiva de alguien que está buscando el voto de este sector de la población para asegurar su reelección en el siguiente período.

Todo paradigma es una construcción histórica. Se basa en un conjunto de elementos reales e imaginados que se registran en los procesos sociales, económicos, políticos o culturales de una región, de una sociedad o de un país durante un período determinado. La imagen del empresario egoísta, interesado exclusivamente en su propio beneficio, data de siglos atrás, de cuando los obreros en las fábricas trabajaban doce, catorce o dieciséis horas diarias sin contar con leyes de protección social. En el Perú, habría que recordar el mecanismo de trabajo de los culíes chinos en el siglo XIX o el del enganche a comienzos del siglo XX, mediante el cual se obligaba a miembros de las comunidades campesinas a trabajar en las empresas mineras o en las haciendas costeñas.

La imagen de los políticos ávidos de poder o corruptos tampoco es reciente. Se origina en las historias de estos personajes asociadas a golpes de Estado para hacerse con el control del gobierno al interrumpir la continuidad democrática, o a maltratos de minorías étnicas o grupos disidentes, o a grandes transacciones financieras realizadas con dineros públicos, o a ejecuciones y masacres de poblaciones enteras para controlar revueltas. En el Perú, habría que recordar las guerras militares posteriores a la Independencia, los fusilamientos de líderes rebeldes como Salaverry, en 1836, el caso Dreyfus y el guano, la matanza de los apristas en 1932, el maltrato a los japoneses durante la Segunda Guerra Mundial, las persecuciones políticas y los sucesivos golpes de Estado a lo largo del siglo XX.

Los paradigmas se encuentran permanentemente sometidos a modificaciones. Se redefinen gradual e imperceptiblemente. En su origen se trata de modificaciones mínimas, marginales. Por ejemplo, la búsqueda por mejorar el nivel salarial de los obreros en la década de 1930, llevada a cabo por los empresarios peruanos del sur del país como resultado del predominio de relaciones serviles en las haciendas serranas, logró influir en la Constitución de 1933 cuando esta reconoció el derecho a los beneficios de los trabajadores de las empresas. Al comenzar el siglo XX, el hacendado Víctor Larco Herrera condujo acciones filantrópicas muy significativas para ayudar a los enfermos mentales en el Perú e influyó en una nueva actitud empresarial. La presencia pública de la mujer a través de la cultura y sus gestos heroicos en circunstancias difíciles para el Perú iniciaron la creación de un contexto que, posteriormente, hizo factible el reconocimiento del derecho del voto a la mujer y su participación decisiva en la vida política. Los elementos dominantes de la estructura paradigmática se arrastran hasta que se ubican en una posición secundaria y abren paso a un nuevo paradigma, aunque los viejos elementos no desaparezcan. 
La responsabilidad social es un nuevo paradigma que orienta el comportamiento de las organizaciones y la percepción de la población con relación a aquellas. Todas las definiciones sobre RS tienen en común que plantean una nueva manera de entender la organización. No es un mensaje cuyo propósito exclusivo sea mejorar su posicionamiento. Es un mensaje, principalmente, para las mismas organizaciones, para sus integrantes, socios, accionistas, gerentes, trabajadores o colaboradores, con el fin de adecuarse a las nuevas exigencias de la sociedad y del mercado.

\section{NUEVA ÉTICA}

La ética es una manera de ser. Cuando actuamos, descubrimos los valores y los afectos que nos mueven. Muchas veces solemos pensar que lo que hacemos no tiene que ver con lo que somos. Por ejemplo, podemos decir que nos pasamos la luz roja del semáforo pero que somos celosos guardianes de las leyes y las normas. $\mathrm{O}$ que las leyes del Congreso son democráticas aunque no hayan sido previamente consultadas con los distintos segmentos de la sociedad. O que también nos preocupamos por transmitir una visión positiva del mundo cuando nuestras informaciones y reportes periodísticos solo destacan las tragedias, las muertes, las derrotas, los escándalos, es decir, el lado lúgubre de la humanidad o de nuestro país. Durante cada instante en el que actuamos le estamos diciendo a los demás lo que somos. Los valores no son las palabras que definen un modo de ser: los valores son las acciones que realizamos. En estas se plasman lo que somos.

La ética puede ser la de la incoherencia. Los seres humanos actuamos en relación con otros. Desarrollamos y tejemos vínculos. Pero no siempre nuestras relaciones siguen un mismo patrón. A veces respetamos escrupulosamente las normas sociales. Otras veces, las desconocemos y nos movemos bajo normas no consensuadas o acordadas. Por ejemplo, rechazamos el «método de la coima» para resolver los juicios y somos duros críticos de la corrupción; inclusive pedimos sanción y castigo para los corruptos. Pero suele ocurrir que, embarcados en un juicio, buscamos apurar la sentencia o adaptarla a nuestra conveniencia, con o sin razón. Se aparece la tentación de pagarle al juez por debajo de la mesa, y muchos lo hacen. El razonamiento detrás de esta acción podría ser el siguiente: «Lo que es malo en los demás merece ser castigado. Lo que es malo en mí merece ser perdonado». O tal como esgrimió alguna vez un presidente peruano: «Para mis amigos, todo; para mis enemigos, la ley».

La ética se mueve en el mundo consciente y en el universo inadvertido. Por lo general, no somos conscientes de los valores que nos impulsan. Más aún, los descubrimos al actuar, al hacer algo. Si lo que domina en nuestra cultura es la ética de la incoherencia, nos resultará muy sencillo pasar de una posición a otra sin sentir culpa o responsabilidad. El problema, por lo tanto, es nuestro universo inadvertido, ese lugar en el que

PARADIGMA,

ÉTICA Y GESTIÓN

(A PROPÓSITO DE

LA RESPONSABILI-

DAD SOCIAL) 
transcurren muchas cosas sin que seamos conscientes de ellas. Gran parte de nuestras relaciones con otros se plasma gracias a ese inconsciente. Se trata de la cultura en la que estamos inmersos. Poner al descubierto ese «lugar oscuro» supone abrir la posibilidad a la ampliación de nuestra conciencia para asumir nuestras responsabilidades y manejar de otra manera las relaciones que establecemos.

La responsabilidad social es una ética de la coherencia. Las organizaciones desarrollan múltiples actividades en diferentes ámbitos y dimensiones. Por ejemplo, si se mira hacia dentro de la organización, se puede observar que existen políticas y prácticas laborales, que el clima interno impacta sobre todos sus trabajadores y que influye en su nivel de satisfacción como seres humanos, en su rendimiento como trabajadores, en la calidad de los productos o de los servicios a partir de los procesos utilizados para su elaboración. Si se mira hacia afuera de la organización, se podrá ver que genera expectativas y situaciones sociales, culturales y ambientales antes inexistentes en la comunidad en la que está presente. Dependiendo de la comprensión que la organización tenga sobre su capacidad de impacto y de las responsabilidades que debiera asumir por ello, desarrollará políticas y prácticas en algunos o en todos esos campos.

La transformación de las prácticas en una organización no solo es un proceso referido a las técnicas productivas. Es, sobre todo, un cambio integral de perspectiva, de valores y afectos, en suma, de paradigma. Pero, si bien el paradigma de la responsabilidad puede ser entendido como una nueva lógica de funcionamiento coherente, esto no siempre ocurre. Dependerá del momento en que la organización se encuentre, de la cultura, de la comprensión que posee la alta dirección de sus responsabilidades, entre otros. De modo que en el proceso de despliegue de las prácticas de responsabilidad social se podrán encontrar organizaciones que trabajan solo uno de los aspectos y transmiten un mensaje de incoherencia con relación al paradigma. Por ejemplo, hay organizaciones que han centrado sus relaciones con las comunidades a partir de vínculos filantrópicos; realizan donaciones en dinero o especie para actividades que solicitan los mismos miembros de la comunidad, pero mantienen una política laboral inadecuada. Así se genera una situación en la que la organización es filantrópica y, al mismo tiempo, injusta en el manejo de las condiciones de trabajo.

La incoherencia es una oportunidad. En toda institución siempre se produce una tensión entre lo tradicional y lo moderno, entre los viejos conocimientos y los nuevos, entre las antiguas formas de apreciación y las que emergen, entre las creencias que vienen del sentido común actual y las del nuevo sentido común que se abre paso. Es una dinámica constante. Precisamente porque las transformaciones no ocurren en un instante, porque transformar implica un proceso de acomodos y reacomodos internos e íntimos, es que surgen distintos grados de incoherencia en organizaciones que asumen prácticas de responsabilidad 
social. Para abordar estos resultados y corregirlos, las organizaciones deben estar permanentemente alertas, observando sus procesos tanto en el campo productivo y técnico, así como en lo cultural, ambiental y social.

Pero la práctica de la incoherencia puede tener un horizonte temporal, una vigencia. Hay que ver su existencia como un elemento positivo, porque expresa las dudas de la alta dirección de la organización, dudas a partir de las cuales se puede descubrir toda la constelación de la responsabilidad social.

\section{NUEVA GERENCIA}

La responsabilidad social representa una nueva forma de gerencia. La emergencia de nuevas tendencias universales afecta la dinámica general de la sociedad y contribuye a redefinir el rol de sus actores e instituciones. Lo que distingue nuestra era de las anteriores es la velocidad de sus transformaciones gracias a la tecnología y las herramientas comunicativas. Asistimos a una etapa en el desarrollo de la humanidad durante la que se manifiesta una distinta manera de concebir y procesar el conocimiento, que, además, tiene repercusiones fundamentales en el mundo de la producción y del trabajo. En otras palabras, para producir, la organización depende cada vez más del conocimiento y del saber de sus trabajadores. Entendemos el conocimiento o saber no solo como información sino como un proceso de valoración-acción que se manifiesta en la producción de la organización. El nuevo conocimiento solo incrementa la productividad del trabajador cuando, dentro de la organización, este se articula al conocimiento de otros trabajadores en función del objetivo de aquella. Por ello el conocimiento no puede permanecer acumulado en los niveles de la dirección de la organización.

Para hacer útil y práctico el conocimiento individual de los trabajadores y el de quienes dirigen la institución, para transformarlo en un saber, se debe contar con una concepción de organización que lo torne factible. La tradicional estructura piramidal mediante la cual el conocimiento nuevo solo era apropiado por los mandos altos de las organizaciones debe dar paso a una forma de organización en la que se administren conocimientos con criterios innovadores. La organización debe ser motivadora, debe generar el clima propicio para un excelente rendimiento y debe permitir que se recojan las iniciativas de los trabajadores para que ellos sientan que su compromiso con el proceso y la organización es realmente apreciado. En organizaciones muy rígidas o poco flexibles, o en climas institucionales poco tolerantes, la productividad del trabajo puede disminuir significativamente o puede no provocar la mejora necesaria.

La productividad no solo es el resultado de un nuevo conocimiento en la dirección y en los trabajadores de una organización. Es, principalmente, una manera de recogerlo y de aplicarlo; es decir, tiene que ver con la manera en que se organiza la entidad. Los trabajadores son su vínculo

PARADIGMA, ÉTICA Y GESTIÓN (A PROPÓSITO DE LA RESPONSABILIDAD SOCIAL) 
más cercano con su entorno. Desde otro ángulo, ellos son la manifestación de la organización ante la sociedad. Si la pirámide permanece con la punta hacia arriba durante la implementación de la visión y de los objetivos, toda la energía y atención continuará fluyendo hacia arriba, lejos de los que conforman su entorno humano. Cuando se desincentiva a los propios trabajadores, se fabrica la disociación y se corre el riesgo de caer en la incongruencia.

El objetivo de las organizaciones es satisfacer necesidades sociales. Para llevar a cabo tal pretensión se organizan bajo una determinada lógica. Hasta hace muy poco dominaba la visión a corto plazo: la preocupación por la más inmediata obtención del máximo beneficio (económico, social, cultural). Además, todo ello ocurría dentro del marco de una organización vertical, en la que la productividad dependía básicamente de la mejora técnica de los equipos y de la optimización de ciertos procedimientos para hacer más eficiente la puesta en marcha o la repetición de las tareas. La nueva significación de la organización en nuestras sociedades está obligando a introducir cambios en esta lógica de funcionamiento. Hoy es necesario tomar en consideración, cuando menos, cuatro dimensiones fundamentales: la económica, la laboral, la ambiental y la de la comunidad.

En el caso de las organizaciones empresariales, estas necesitan generar utilidades para seguir operando. Su sostenibilidad en el tiempo depende de ello. Pero lograrlo requiere mejorar la productividad de sus trabajadores. Este es el desafío clave que marca la diferencia entre las empresas cuando se trata de desarrollar sus ventajas competitivas. Los nuevos paradigmas y la revolución tecnológica a la que asistimos han puesto al conocimiento como el eje de la capitalización de las empresas. Para competir en un mundo globalizado, es necesario no solo motivar a los trabajadores a través de mejoras salariales o cambios en las condiciones de trabajo. Se necesita, incesantemente, ofrecerles capacitación y acceso al nuevo saber que se va abriendo paso.

Pero la aplicación eficaz de los nuevos conocimientos adquiridos requiere de una organización que permita a los trabajadores una más decisiva participación en la definición de los procesos internos de su organización. La estructura piramidal de control vertical necesita una reformulación para dar paso a una descentralización institucional y a la promoción de liderazgos internos. Los trabajadores que se vinculan a las organizaciones, sin distinguir la naturaleza de su vínculo, deben encontrar cada vez más espacios de realización personal y no solo un buen salario.

En su accionar, las organizaciones generan impactos sociales de diversa naturaleza, lo cual depende de la actividad que desarrollan. La identificación de tales efectos, negativos o positivos, es fundamental para comprender el sentido de su comportamiento. Algunas repercuten sobre el medio ambiente; por ejemplo, contaminan a través de la emisión de fluidos o de gases que pueden ser tóxicos directamente para el ser humano 
o para el entorno. Otras afectan el nivel de empleo de una región, sea porque se van o porque llegan. Otras introducen pautas culturales nuevas que favorecen o colisionan con las establecidas tradicionalmente. Una buena relación con la comunidad, que reduzca la tensión negativa y favorezca una mayor estabilidad a largo plazo, obliga a la innovación o a la modificación de procesos productivos y organizacionales.

La competitividad y la productividad de una organización no solo dependen de sus ventajas técnicas. También son fundamentales la identificación de los trabajadores con su organización y la estabilidad social de la comunidad en la que se asienta. Una mayor identificación de los trabajadores está asociada a la motivación que permite el clima interno de la organización, es decir, el acceso al conocimiento, la delegación de autoridad a través de la descentralización y la posibilidad de hacer emerger liderazgos internos para mejorar el proceso productivo y el acceso a los distintos componentes del entorno. Pero también interviene, especialmente si los trabajadores son residentes del propio lugar en el que se asienta la organización, el vínculo positivo con la comunidad.

\section{EL PROCESO DE LA RESPONSABILIDAD SOCIAL EN EL PERÚ}

\section{Antecedentes}

Después de la Guerra del Pacífico (1879-1884), el Perú ingresó en una nueva etapa de desarrollo. En la sierra, las haciendas se expandieron mediante la expropiación de sus tierras a las comunidades indígenas ${ }^{3}$. En la costa, crecieron a expensas de pequeñas propiedades agrícolas ${ }^{4}$. En los centros urbanos, emergió un sector empresarial cuyo objetivo era la expansión del mercado interior ${ }^{5}$, limitado por la presencia del latifundio, que mantenía relaciones serviles o semiserviles.

Este conjunto de elementos llevó a los sectores empresariales más modernos a plantear su transformación. Bustamante de la Fuente, industrial sureño de la década de 1930, sostenía que el Perú necesitaba «resolver el problema indígena que es cultural y económico. Hay que educar e instruir al indio colocándolo en condiciones de producir y consumir riqueza, para libertarnos del enorme peso muerto que hoy soportamos, cerca de cuatro millones de hombres absolutamente nulos para la nacionalidad» ${ }^{6}$. Más adelante, agregaba que había que abolir

4 KLAREN, Peter. Las haciendas azucareras y los orígenes del APRA. Segunda edición.Lima: Instituto de Estudios Peruanos, 1976.

5 Caravedo, Baltazar. «El problema del centralismo en el Perú Republicano». Allpanchis, vol. XII, № 13, 1979, pp. 19-50, Cusco.

6 Caravedo, Baltazar. «Poder central y descentralización. Perú 1931». Apuntes, № 9, 1979, p. 118, Universidad del Pacífico, Lima.

PARADIGMA,

ÉTICA Y GESTIÓN

(A PROPÓSITO DE

LA RESPONSABILI-

DAD SOCIAL) 
«la costumbre de que el indígena preste servicios gratuitos en compensación del derecho de pastoreo de su ganado en la finca del patrón»?

Paralelamente a las demandas de los empresarios urbanos no limeños, en la capital de la república surgió un movimiento obrero que reclamaba las ocho horas como tope a su horario de trabajo. En 1918 se aprobó la jornada laboral de ocho horas. En 1926 el Gobierno creó la Inspección de Higiene y Seguridad Industrial, cuyo propósito era defender la salud de los obreros. Hacia 1929, su director sostenía lo siguiente:

Durante mucho tiempo se creyó que la producción variaba conforme duraba la jornada de trabajo, que cada hora que la máquina se movía significaba ganancia y cada momento de ocio era una pérdida. Por eso, en los primeros años del sistema de factoría, las jornadas de doce, catorce y aun de quince horas al día eran la regla [...]. En los últimos años ha ganado popularidad la jornada de ocho horas [...]. Lo cierto es que el obrero debe tener descanso suficiente para recuperar sus fuerzas e ir al trabajo con nuevo vigor ${ }^{8}$.

Más adelante agregaba: «La vida normal de la familia no puede subsistir cuando los hombres y las mujeres gastan todas sus energías en la producción industrial»?.

Se fue generando una dinámica en la que predominaban dos preocupaciones: expandir el mercado interior y crear un clima de trabajo apropiado para el mayor rendimiento de los trabajadores. Con esos antecedentes se organizó la Conferencia Económica del Sur, en 1932, en la que participaron los gremios empresariales de los departamentos de Arequipa, Cusco, Puno, Moquegua y Tacna. El empresariado arequipeño, interesado en expandir el mercado interno, cumplió un papel fundamental en los planteamientos de mejora salarial para aumentar el poder adquisitivo de los trabajadores, para proteger sus condiciones de trabajo y para crear una relación armoniosa dentro de la empresa. El Congreso Constituyente de 1931 incorporó tales preocupaciones en la Carta Constitucional, aprobada en 1933. De acuerdo a este documento, varios de sus artículos rescatan esta perspectiva. Por ejemplo, su artículo $44^{\circ}$ decía: «Es prohibida [sic] toda estipulación en el contrato de trabajo, que restrinja el ejercicio de los derechos civiles y sociales». Y su artículo 45ำ señalaba: «El Estado favorecerá un régimen de participación de los empleados y trabajadores en los beneficios de las empresas».

\section{La creación de CADE}

Desde los inicios de la década de 1950 hasta fines de la década de 1960, el Perú experimentó un crecimiento económico constante. En

7 Ibíd., p. 119.

8 Caravedo Prado, Baltazar. La reforma psiquiátrica en el Perú. Lima: Centro de Investigaciones Psiquiátricas y Psicológicas, 1985, p. 202.

9 lbíd. 
el Congreso se había discutido y aprobado la Ley de Promoción Industrial en 1959. Se empezó a desarrollar muy significativamente el sector industrial de la economía. Durante su primer gobierno, Belaunde había fomentado y creado los parques industriales con el propósito de descentralizar el crecimiento industrial. Algunas actividades productivas, como la pesquera, habían entrado en una dinámica que se conoció como el «boom pesquero».

La industria, con miras al mercado interno, también se expandió. Se promocionó el consumo de productos nacionales. Durante el proceso de plasmación de este contexto, se decidió crear la Conferencia Anual de Ejecutivos (CADE), instancia que abordaba los problemas nacionales y los empresariales. Al comenzar la década de 1960, Carlos Mariotti, fundador de CADE, afirmó en su discurso inaugural: «Si las responsabilidades del hombre de negocios han sido siempre muy grandes, no cabe duda [de] que los problemas de la hora actual han intensificado las exigencias propias de la función ejecutiva, tanto en el aspecto técnico y económico como, principalmente, humano y social $»^{10}$. En ese mismo discurso proseguía de la siguiente manera:

Creo sinceramente, señores, que mucho, si no todo, depende de nosotros mismos, del espíritu que nos anima, de nuestras reservas de valor moral, de nuestra voluntad de encontrar soluciones justas y razonables que pueden dar nueva vida y tal vez mayor sentido humano y social a nuestra civilización occidental, a la filosofía de la libre empresa y a ese bien, todavía más valioso, que no se puede perder: la libertad individual obtenida en función de un amplio respeto al derecho de los demás ${ }^{11}$.

Se puede decir que, para Mariotti, el empresario debe asumir un doble rol: ser orientador de la empresa y ser un líder social preocupado por «el otro» ${ }^{12}$.

\section{La década de 1970}

La década de 1970 estuvo marcada por la acción del Gobierno Militar que tomó el poder en octubre de 1968. Nos interesa destacar algunas características de esta etapa. Se alteró sustantivamente la estructura de propiedad del país; se expropiaron haciendas y se transfirieron a unidades productivas conducidas por campesinos y obreros agrarios ${ }^{13}$. Se estatizó la gran minería y se obligó a las empresas industriales a ingresar en una lógica mediante la cual los obreros participaban en los órganos de decisión de las empresas, además de obtener, conforme se capitalizaban, parte de su propiedad ${ }^{14}$. Primó en la sociedad peruana una

10 CADE, 14 de septiembre de 1961. Tomado de CARAVEDO, Baltazar. Empresa, liderazgo y sociedad... Óp. cit., p. 49.

11 lbíd.

12 Ibíd.

13 En la sierra, fueron las Sociedades Agrarias de Interés Social (SAIS) y en la costa las Cooperativas Agrarias.

14 El mecanismo se conoció con el nombre de «comunidades laborales».

PARADIGMA,

ÉTICA Y GESTIÓN

(A PROPÓSITO DE

LA RESPONSABILI-

DAD SOCIAL) 
visión estatizante y se redujo el peso del sector empresarial privado en el desenvolvimiento de la economía. En 1978, para iniciar el retiro de las Fuerzas Armadas del Gobierno, se convocó una Asamblea Constituyente. La pretensión de los militares fue que se elaborara una Constitución que plasmase las reformas que habían introducido.

La Constitución de 1979 aprobó una concepción económica contradictoria. En primer lugar, estableció que «el Estado promueve el desarrollo económico y social mediante el incremento de la producción y de la productividad, la racional utilización de los recursos, el pleno empleo y la distribución equitativa del ingreso» ${ }^{15}$. Luego, sostuvo que «el Estado formula la política económica y social mediante planes de desarrollo que regulan la actividad del sector público y orientan en forma concertada la actividad de los demás sectores. La planificación una vez concertada es de cumplimiento obligatorio» ${ }^{16}$. La importancia de la planificación se hizo evidente. No obstante, más adelante se decía: «La iniciativa privada es libre. Se ejerce en una economía social de mercado» ${ }^{17}$. Y posteriormente: «El Estado reconoce la libertad de comercio e industria» ${ }^{18}$. La idea de la economía social de mercado es una concepción distinta a la del Estado intervencionista, y es un puente a la idea de empresa socialmente responsable ${ }^{19}$.

\section{La década de 1980}

En el aspecto democrático y de seguridad, la década de 1980 estuvo marcada por dos procesos contradictorios. De un lado, la emergencia y la continuidad democrática de los gobiernos nacionales, elegidos conjuntamente con la reinstauración de las elecciones en el ámbito municipal, suspendida durante el Gobierno Militar de la década anterior. De otro, el inicio de las acciones terroristas que ensangrentaron el país durante más de una década. Para algunos se trató de una guerra interna. Sus alcances y consecuencias han sido investigados y presentados por la Comisión de la Verdad y la Reconciliación ${ }^{20}$.

En el aspecto económico, si bien se redefinió el peso del Estado, no llegó a reducirse drásticamente con relación a la década anterior. En los medios intelectuales se empezó a brindar mayor importancia a la pequeña empresa y al mercado ${ }^{21}$. Ideológicamente, se abrió el espacio para un mejor posicionamiento de la visión liberal y se tendió a agotar el discurso estatista y planificador. En el aspecto político, el movimiento que lideró Vargas Llosa colocó en el terreno de los intereses públicos la necesidad del mercado y de la participación de la empresa privada como eje fundamental en el desarrollo.

15 Artículo 110 de la Constitución de 1979.

16 Artículo 111.

17 Artículo 115.

18 Artículo 131.

19 CARAVEDO, Baltazar. Reconstruyendo el camino. Estado, economía y regiones en el Perú de los 90. Lima: SASE, 1992, p. 108.

20 Véase el Informe de la Comisión de la Verdad y la Reconciliación.

21 Véanse tos trabajos de Fernando Villarán, Hernando de Soto, entre otros, publicados durante la década de 1980. 
Algunos líderes empresariales habían empezado a abordar temas relacionados con la responsabilidad social de la empresa, especialmente en los inicios de esta década. En la Memoria Anual de 1982 de la Sociedad Nacional de Industrias (SNI), su presidente sostuvo ${ }^{22}$ :

Lo que a nuestro juicio debemos hacer los empresarios se describe a continuación:

- Tratar a toda costa de mantener un nivel razonable de empleo

- Mantener la empresa lo más productiva posible para cumplir todas nuestras responsabilidades sociales

- Promover una eficaz comunicación con nuestro personal de todos los niveles, tanto en lo que se refiere a la empresa, como en los aspectos sociales y económicos de la comunidad

- Pugnar porque la empresa no sea un simple centro de producción sino que tenga también un pleno sentido humano ${ }^{23}$

En aquellos años, la SNI demostró una preocupación ambiental. En 1983 se premió a la empresa Metalúrgica Peruana S.A. con una «placa de defensa del medio ambiente». Al fundamentar la entrega del referido reconocimiento, se dijo: «Se tuvo en consideración que la mencionada empresa ha instalado un costoso sistema de extracción y purificación de humos e incentiva con su accionar este tipo de inversiones que normalmente no se justifican bajo los métodos tradicionales de medir la rentabilidad, pero que representan, a no dudarlo, un positivo beneficio para la colectividad ${ }^{24}$.

\section{La década de 1990 y el advenimiento del nuevo siglo}

Este período estuvo claramente marcado por el proceso de desestatización del aparato público. Las empresas anteriormente expropiadas fueron privatizadas y el sector privado, a través de sus capitales, potenció su presencia gremial y su manejo gerencial. Es necesario destacar, también, que al comenzar la década de 1990 se pudo apreciar un grupo generacional nuevo - de entre 35 y 45 años- de empresarios que asumieron puestos gerenciales o de liderazgo en empresas grandes y medianas o en organizaciones gremiales. Un contingente significativo con estudios de postgrado en universidades norteamericanas y europeas, por lo que traían al Perú una visión y formación empresarial moderna.

Hacia septiembre de 1992, un grupo conformado principalmente por unos cincuenta empresarios jóvenes decidió explorar la posibilidad de crear una visión a largo plazo que permitiese orientar a la sociedad peruana, dotarla de estabilidad social y formular políticas a partir de una visión que fuese una suerte de acuerdo nacional —aunque este concepto no fue empleado-. El grupo de empresarios jóvenes se reunió durante casi dos años, al cabo de los cuales (agosto de 1994) presentaron su

PARADIGMA,

ÉTICA Y GESTIÓN

(A PROPÓSITO DE

LA RESPONSABILI-

DAD SOCIAL) 
visión del Perú hacia el 2021, año de celebración del bicentenario de la independencia nacional. Se autodenominaron Perú 2021. Una de sus primeras afirmaciones fue:

En el mundo actual, el empresario es el principal agente de desarrollo, de la elevación y expansión del bienestar y de la calidad de vida humana. El empresario es el principal creador de riqueza personal, social y cultural. En tal sentido, cada empresario debe ser un líder, un inspirador, que inicie esa transformación en sí mismo y en su propia empresa como base de este esfuerzo integral de reingienería nacional ${ }^{25}$.

Más adelante, en el mismo documento, se lee:

El objetivo final es que el Perú llegue al 2021 [...] como un país desarrollado, respetado, confortable, capaz de ofrecer conocimiento y valor agregado, con un pueblo que disfrute de un alto nivel y calidad de vida y cuyos paradigmas y culturas hayan cambiado substancialmente a un sentido de comunidad social y solidaria, rigor ético, respeto a la ley y a los derechos ajenos; actitud de ahorro, trabajo, innovación y éxito; de respeto a la naturaleza, al ser humano y a la propiedad privada; con empresas que trascienden a sí mismas y hagan de la producción un servicio; donde primen la competencia y el sentido de logro, en vez de proteccionismo y privilegio paternalistas, y donde la persona sea la razón de ser de la sociedad y del Estado ${ }^{26}$.

Al finalizar la década de 1980, para un sector de organizaciones que antes se opuso radicalmente al capitalismo, la empresa privada no era percibida como enemiga del desarrollo o como la expresión de un interés meramente egoísta. La crisis del modelo estatista impuesto por el Gobierno Militar en los años setenta y la movilización y prédica de grupos sociales e intelectuales en favor del libre mercado y la propiedad privada contribuyeron a la creación de este naciente nuevo clima. Cabe destacar aquí, solo a modo de ilustración, el desarrollo de la ONG Centro de Asesoría Laboral (CEDAL) que, de consultora legal de pliegos de reclamo de los trabajadores sindicalizados, pasó a tener un papel de promotora de la responsabilidad social en el medio laboral, y que se especializaría luego en la herramienta conocida como SA 8000. Otra ONG que también experimentó este proceso fue Labor, entidad que, después de haber sostenido una visión de confrontación radical con las empresas mineras durante la primera mitad de los años noventa, pasó a liderar, conjuntamente con algunos empresarios de la minería, el Grupo de Diálogo Minero.

Hacia 1986 se creó la Sociedad Peruana de Derecho Ambiental (SPDA), organización dedicada a promover una legislación apropiada y la defensa del ambiente desde un punto de vista legal. Durante la misma década nació la Fundación Peruana para la Conservación de la Naturaleza (FPCN), 
con la finalidad de establecer y de proteger áreas naturales. Ambas organizaciones tuvieron capacidad para vincularse primero al Congreso de la República y, posteriormente, al sector empresarial, el cual les permitió un liderazgo mayor. Gracias al asesoramiento de estas entidades, fue posible el nacimiento del Código del Medio Ambiente, en 1990, aunque inicialmente no fue bien recibido por el empresariado.

El código introdujo la figura de los estudios de impacto ambiental y el de la participación ciudadana en temas relacionados. La normatividad ambiental, con dificultades y tropiezos, logró incorporar una inquietud hacia el medio empresarial en temas que no estaban en el centro de sus preocupaciones de negocios. En este sentido, contribuyó a descentrar o ampliar el foco de la actividad empresarial.

Desde 1985, las ONG técnicas, especialistas, sin historia ni parentesco o relación alguna con las ONG portadoras de un discurso implícita o explícitamente confrontacional habían empezado a tener un peso relativamente mayor en el mundo de aquellas sin fines de lucro. Esto se puso en evidencia en propuestas, proyectos o declaraciones de las ONG. Se dijo: «Una asociación entre organizaciones productivas de base, orientada tradicionalmente por una ONGD, y una empresa particular podrían generar el nexo necesario para mejorar los efectos de los proyectos productivos, y arrastrar a otras entidades similares a una dinámica nueva» ${ }^{27}$.

Los elementos destacados influyeron en la creación de un clima que luego permitió posicionar el concepto de responsabilidad social en el mundo empresarial. No obstante, habría que complementar esta apreciación con otros procesos que, iniciados en la década de 1990, han tomado más fuerza a partir de 2000. Nos referimos a la convocatoria a los simposios de responsabilidad social iniciados en 1996 por Perú 2021. En estos eventos, las empresas, por primera vez, empezaron a mostrar sus estrategias sociales o sus acciones filantrópicas y de inversión social. Las investigaciones desarrolladas por SASE desde 1997 y 1998 dieron pie a la posibilidad de otorgar premios sobre la base de un ranking, lo cual despertó un interés por competir en el terreno de lo social. Las publicaciones de SASE, Perú 2021 y la Universidad del Pacífico, entre 1996 y 1998, fueron pioneras en el tema. A partir de 1999, bajo el liderazgo de Felipe Portocarrero, se inauguró en la Universidad del Pacífico una serie de publicaciones sobre Responsabilidad Social, que en la actualidad llega a veintinueve títulos editados.

Desde 1998, cuando AVINA tomó contacto con algunos líderes sociales y empresariales, influyó en el desarrollo de la responsabilidad social en el Perú ${ }^{28}$. En 1999, gracias a ella ${ }^{29}$, Perú 2021 desplegó una serie de

27 Caravedo, Baltazar y Armando PILLAdo. Cooperación internacional, ONGDs y desarrollo. Lima: SASE, ANC, IIN, PEMTEC e IDEAS, 1993, p. 91.

28 Se trata de Jorge Caillaux (SPDA), de Manuel Sotomayor (Perú 2021) y de Baltazar Caravedo (SASE).

29 En esta iniciativa también colaboró la Inter-American Foundation, aunque en menor medida. 
actividades para reelaborar su visión. Organizó consultas en catorce ciudades en las que participaron alrededor de 560 líderes locales y regionales. Este proceso supuso una oportunidad para sensibilizar a los gremios empresariales locales en el tema de responsabilidad social. AVINA también apoyó otras iniciativas que provenían del mundo de las ONG para promover esta perspectiva: se alió con la Asociación Peruana de Consumidores (ASPEC) para incitar el consumo responsable; con CIDATT, en $\mathrm{Lima}^{30}$, para promover el transporte responsable; con las organizaciones impulsoras de la Macro Región Sur, a partir de lo cual redefinió, además, el concepto de descentralización en tanto mecanismo de integración comercial con los países vecinos; con CEDAL para sensibilizar a los trabajadores en la nueva perspectiva que se abría paso; con la Universidad del Pacífico para desplegar y desarrollar el tema en el mundo académico; con la SPDA para colaborar con la investigación y la asesoría ambiental en el Congreso de la República; con la ONG Labor para apoyar el Grupo de Diálogo Minero; con el Instituto Natura para desarrollar un acercamiento educativo entre empresarios y organizaciones de la sociedad civil en Chimbote; y con la Red de Responsabilidad Social, en la que intervienen Perú 2021, Visión Solidaria y Guida de Gastelumendi, para promover el denominado «mes de la responsabilidad social».

Otras iniciativas independientes han contribuido sustancialmente a la creación de un contexto favorable a la responsabilidad social. De un lado, en los discursos de los líderes gremiales empresariales se utiliza cada vez más el término. De otro, ha habido cierta influencia en los medios de comunicación, especialmente en los radiales, como ocurre con el Grupo RPP: este promueve, desde hace unos nueve años, un premio de integración y solidaridad que distingue a personas, instituciones y empresas por las acciones que despliegan. En tercer lugar, ha ingresado en iniciativas relacionadas con jóvenes profesionales que desempeñan roles empresariales, como es el caso de Gestionarse. Finalmente, se ha materializado en el plano académico: tal es el caso de la Universidad Católica, primero a través de Denis Sulmont, quien introdujo el tema en el ambiente académico ${ }^{31}$ y, luego, a través del Diplomado de Responsabilidad Social del Instituto de la Calidad (en alianza con SASE), Y de la Maestría de CENTRUM.

Estos procesos han conducido al Perú a su situación actual. Si bien la responsabilidad social de la empresa se ha convertido en un tema y un proceso indispensables para la transformación social, todavía se requiere extenderlos a otras organizaciones de la sociedad. 